\section{Nomear e compreender a pobreza no Brasil contemporâneo}

LEAL IVO, Anete Brito. Viver por um fio: pobreza e política social. São Paulo/Salvador, Annablume/ CRH-UFBA, 2008. 256 páginas.

\section{Cibele Saliba Rizek}

Este livro é a obra madura de uma pesquisadora que vem dedicando ao longo da vida um esforço de compreensão de questões e inquietações que compõem uma obra(produção) que ganhou a clareza, o caráter e a escritura de alguém cujas habilidades foram forjadas pelo ofício de ensinar sociologia. Trata-se, assim, de um livro generoso, em que se explicitam as dimensões conceituais, bem como os caminhos e os atalhos que permitem perseguir uma questão, seus vínculos e articulações com outras questões, até que um desenho, uma conformação possa ser percebida. Nem bem esse trabalho se conclui, outra dimensão se anuncia: trata-se de perseguir então o modo pelo qual essa mesma questão - híbrida por natureza se transforma e se modula no tempo. Assim ganha densidade, ao longo das páginas redigidas de forma concisa e elegante, a questão social - ou antes, no caso em tela, a pobreza como a questão social brasileira, pelo menos para aqueles que continuam fiéis a uma longa e profícua tradição de pensamento sobre o país, tradição que produziu o que há de melhor na sociologia crítica brasileira. Anete Brito Leal Ivo é herdeira dessa tradição crítica, encarando o desafio de fazer dialogarem teoria e empiria nesse texto construído a partir de parâmetros clássicos, sobre um objeto denso e contemporâneo que acabou por se transformar em um belo livro.

$\mathrm{O}$ que faz de Viver por um fio um belo livro? Sobretudo o fato de que nele a autora não economiza nem simplifica as grandes discussões e controvérsias que constituem os campos temáticos que a construção do argumento atravessa e propõe. Esses campos temáticos vão se desenhando como questões teóricas e empíricas da maior importância para as ciências sociais e para a reflexão sobre o Brasil nesses tempos de um encolhimento da crítica e da discussão, sempre em face do menos pior. Trata-se, então, de encarar a dimensão de um conjunto de crises - teóricas e conceituais, crises cognitivas, crises de nominação que atravessam e qualificam o debate em torno da pobreza, de um lado, e das políticas sociais, de outro.

Assim como não se jogam para debaixo do tapete os embates conceituais, também não se economizam os apontamentos e as imbricações presentes na consideração de mediações que redefinem ou redesenham os objetos centrais do livro. As políticas sociais ocupam esse lugar - constituindose, portanto, em " mediações que substituem as antigas estruturas de regulação de caráter societário e a sua legitimação tradicional e 'autoritária"'. Como dimensão fortemente vinculada ao campo da modernidade, as idéias de bem-estar, autonomia e igualdade diante da lei, vinculadas à consciência e à reflexividade modernas são "fundamentos da objetividade, não se constituem apenas como ' mitos', mas integram o campo das práticas sociais como 'operadores' ou 'reguladores' normativos e como expressão de 'finalidades"' (p. 54), fazendo-se valer como horizontes que definem a questão social como problema sociológico, como parte desse social, como invenção moderna do social.

Os capítulos de natureza mais conceitual desdobram-se em uma reflexão sobre a sociologia como razão teórica e (deixar razão)prática. Os parâmetros conceituais mais significativos dessa invenção moderna do social - tão bem flagrada por Hannah Arendt - evocam os principais embates sobre o pauperismo que povoam autores como Tocqueville, Marx e Engels e Simmel, além do traçado e dos caminhos que nos conduzem da grande reflexão teórica para uma "sociologia da adaptação" e para a legitimidade das formas de contagem, classificação e controle da pobreza. O paradigma da igualdade (Tocqueville), o paradigma da exploração (Marx e Engels) e o paradigma da dádiva (Simmel) apresentam subsídios para "os limites do debate atual sobre a natureza das proteções sociais. Além das questões relativas à abrangência de tais soluções, especialmente nas sociedades periféricas, em que a grandeza quantitativa do 'excedente' (setor informal) torna ainda mais urgente e, ao mesmo tempo, mais complexa a ação do Estado, o confronto dessas colaborações recoloca, no centro do debate as relações intrínsecas e contraditórias entre a proteção da cidadania e o universo do trabalho e dos trabalhadores. Ou seja, até que ponto a generalização dos 'mínimos', nos programas de renda mínima de cidadania, por exemplo, contribuem para reduzir formas de integração no âmbito da sociedade 
do trabalho ou contribuem, igualmente para aprofundar as condições das desigualdades sociais?” Perseguindo esses paradoxos, Anete Ivo nos dá alguns breves flashes de um debate que remonta à aurora da modernidade, perpassa autores e propositores como Bentham e Owen e sinaliza para a atualização e a reatualização de uma polêmica inconclusa que atravessa a montagem, a narrativa e os projetos que conferiram forma e sentido à questão social e seus paradoxos, bem como seus desdobramentos contemporâneos. Das grandes questões às concepções de "pobreza, desigualdades, exclusão e vulnerabilidade social" como "práticas cognitivas" e como "atos políticos", a autora mostra que essas "noções impõem normas de percepção do próprio objeto, em seu processo de apropriação, que se inscrevem como realidade, conformando a prática dos sujeitos sociais. Assim, a pesquisa e as estatísticas formuladas por instituições, como o Estado, articulam-se diretamente com o mundo social e constituem um construto que resulta e interfere, constantemente, sobre as práticas de atores e agentes sociais. Mas a objetivação do pensamento científico, quando se transforma apenas na agregação de informações, sem referências às condições de produção da história social, institui-se apenas como técnicas dissociadas das formas concretas como se reproduzem a política e o social" (p. 107).

Chegamos finalmente ao Brasil, ou mais propriamente ao enigma brasileiro da questão social, como enuncia a autora. Essa enunciação, se não fala por si, deixa entrever dimensões que definem as relações sociais, econômicas e políticas, sua forma, suas permanências e redefinições no Brasil. Nesse capítulo, o leitor pode revisitar textos clássicos que recompõem de modo bastante claro as questões históricas que emolduram as relações entre pobreza e industrialização, pobreza e suas expressões urbanas desde a colônia, bem como o binômio que ocupou parte significativa do debate das ciências sociais na segunda metade do século XX: os vínculos contraditórios entre desenvolvimento e pobreza. Essa discussão de escopo macrossocial desenha e redesenha a pobreza como marginalidade, massa marginal, trabalho excedente, exclusão e apartheid social, entre outras designações. Como sempre, seguindo as preocupações atentas de Anete Ivo, as dimensões cognitivas, os sentidos subjacentes a cada uma dessas designações são alvo de questões e investimentos. Nesse capítulo, especialmente, encontramos uma pesquisadora madura que discute com tranqüilidade as muitas faces da reflexão brasileira sobre a pobreza através de um caminhar por dentro das contribuições mais ou menos díspares, mais ou menos convergentes da sociologia no Brasil. A sistematização desse debate, com os vários elementos trazidos pela autora, é um reencontro com as questões colocadas em tela pelas injunções brasileiras no âmbito das ciências sociais. Aqui, em especial, um tipo raro de erudição se faz notar não como exercício pernóstico, mas como contribuição real para a compreensão dos parâmetros que vinculam um objeto - a pobreza como enigma brasileiro - e o pensamento social, em suas imbricações políticas. Um belo exemplo é a discussão sobre as categorias subemprego ou subocupação entre os anos de 1970 e 1980. Anete Ivo menciona então o uso das expressões como "trabalhador por conta-própria" ou "trabalhador independente" ou ainda "pequeno produtor independente" utilizadas cada vez mais na medida em que "deixam de ser considerados como 'ociosos' ou 'desocupados', para serem vistos como trabalhadores, ainda que sobrevivendo em níveis de exploração e pobreza extremados, dada a economia de subsistência e a economia informal urbana" (p. 133). Assim, modulam-se as dimensões e os significados da pobreza e do enigma brasileiro com algumas das passagens que conduzem do indolente à massa marginal, dessa marginalidade à condição de trabalhador mesmo que na informalidade, do trabalhador informal ao excluído e da exclusão como fetiche à condição de apartação social. Mas as relações entre as palavras e as coisas, os modos de enunciação e de designação acabam por se configurar como um segundo enigma que se repõe e se redesenha no horizonte das ciências sociais no Brasil.

Esse breve resumo do percurso inicial do livro nos conduz à segunda parte, em que a análise toma como problema central a reconversão do social no Brasil contemporâneo. Uma primeira questão é como, a partir de que critérios de periodização, se pode falar de um Brasil contemporâneo. Há um ponto de inflexão em meio a permanências e redefinições da trama de desigualdades? $\mathrm{Na}$ introdução dessa segunda parte, Anete Ivo localiza suas questões centrais e parece responder a essa indagação da forma que se segue: "Frente à aparição do desemprego estrutural dos anos oitenta e noventa, como fenômeno de 'massa', afetando o núcleo estável dos trabalhadores protegidos do mercado de trabalho, 
e diante de uma herança de elevados níveis de desigualdade e pobreza, e da reprodução do mercado de trabalho informal no Brasil, quais as implicações sociais e políticas das novas políticas sociais de transferência de renda, em sociedades de capitalismo periférico, como o Brasil, que só recentemente transitou para um regime democrático? A segunda parte deste livro busca analisar, portanto, os constrangimentos estruturais, particularmente a partir da década de oitenta, no contexto da globalização e das mudanças institucionais do Estado e seus efeitos sobre a constituição do 'social', no Brasil, os quais expressam o paradoxo da modernização das instituições políticas e ganhos de cidadania, num contexto de desregulação do mercado de trabalho, aumento do desemprego e reformas de um Estado social (ainda inconcluso), o qual, a partir da década de 2000 reorienta-se para uma ação prioritária de focalização sobre os mais pobres" (pp. 143-144).

Mais uma vez é na estratégia de cruzar olhares e dimensões sociais, econômicas e políticas em seus vínculos e articulações que se ancora o desafio de flagrar os processos que armam a questão social brasileira nas últimas duas décadas, em que têm início os caminhos de volta das novas tendências liberais na reforma do Estado social, jamais concluído no Brasil.

Enigmas e dilemas voltam a povoar essas páginas em que as injunções contemporâneas recebem um denso tratamento. Trata-se da questão da pobreza como cifra da questão social, e desta como problema público em uma consolidação democrática tardia que acontece entre um horizonte passado que parece não valer mais - a construção tardia da assimilação cidadã pela constituinte de 1988 - e um horizonte presente de encolhimento da construção democrática, crescentemente circunscrita a uma "democracia de mercado". Quais as novas dimensões do viver por um fio? Ao que tudo indica, a autora mostra, pela utilização de dados e informações que chegam até 2006 e, portanto, apreendem o último ciclo de crescimento econômico e de consumo, que o fio, a corda bamba em que se equilibram parcelas nada desprezíveis da população, parece ter se monetarizado consideravelmente, modulando a condição dos que nela vivem de outro modo. Novos pobres, vulneráveis, assistidos, públicos-alvo de políticas focalizadas e cada vez mais constituídas sob o signo da "eficiência" montam um quadro de complexidades que imbricam inclusão política e exclusão econômica, direitos e seu universo e monetarização, consumo como signo de inclusão, eqüidade e flexibilização da proteção social. Para além dessa análise, voltam também enriquecidos pelo confronto com a empiria os âmbitos conceituais e intermediários que dizem respeito à caracterização da sociologia como razão teórica e a crítica da sociologia como razão prática, como ciência da adaptação a um real visto como mera positividade. As palavras finais de Anete Brito Leal Ivo apontam para uma forma de pensar a produção das ciências sociais que não ignora os obstáculos e os desafios colocados pelas transformações contemporâneas, que não as dissolve nas velhas antinomias brasileiras como se não houvesse nada de novo no terreno das desigualdades e da pobreza. Assim, a autora aponta que " as transferências monetárias representam melhoria de condições de vida (especialmente daqueles na linha da indigência) e dinamizam a economia popular dos pequenos municípios, mas não são potentes para alterar as relações sociais vigentes, de enormes desigualdades, reproduzindo uma massa de trabalhadores mantidos na esfera do autoconsumo e da necessidade. As políticas sociais de caráter universal, vinculadas à educação e à saúde - ou seja entitlements -, no estágio em que se encontram no Brasil, ainda são insuficientes para lançar uma estratégia sustentada de desenvolvimento social com equidade. O desafio é superar-se o precário estágio da necessidade e da auto-reprodução dos trabalhadores brasileiros, sob os mínimos dos mínimos, para um real estágio de capacidades para a liberdade e o desenvolvimento" (p. 240). Necessidade e liberdade mais uma vez se combinam na invenção híbrida e problemática da questão social brasileira, assim como de suas possibilidades de expressão e manifestação política e/ ou de sua redução à sociedade pensada como técnica, como adaptação, como pura eficiência.

CIBELE SALIBA RIZEK é pesquisadora do Centro de Estudos dos Direitos da Cidadania, docente do Departamento e do Programa de Pós-graduação em Arquitetura e Urbanismo da EESC - USP e colaboradora do Programa de Pós-graduação em Sociologia da Universidade Federal de São Carlos. E-mail: cibelesr@uol.com.br. 